\title{
Physiological response of Nigerian indigenous cocks fed diet with graded levels of tumeric (Cucumma longa)
}

Urom, S. M. O. C., Inyang, E. C., * Onunkwo, D. N and Ewa, J. E College of Animal Science and Animal Production, Michael Okpara University of Agriculture Umudike, Abia State, Nigeria

*Corresponding author: donunkwo1@gmail.com, +2348033388622

Abstract

This study was conducted to evaluate the physiological response of Nigerian indigenous chicken (cock) fed graded levels of Tumeric Rhizome Powder (TRP). Sixty (60) adult local cocks divided into 4 groups with 15 birds in each group, replicated into 3 of 5 birds per replicate in each treatment group were used for the study. The birds in the experimental groups designated as $T_{1}, T_{2}, T_{3}$, and $T_{4}$ were fed with TRP supplemented diet at various inclusion levels of 0.0, 0.25, 0.50 and 0.75\%, respectively for 8 weeks. From the results obtained, the growth performance and the relative organ yields were significantly $(p<0.05)$ enhanced, with an average weight of $121.33 \pm 14.70$ of the experimental birds in the Turmeric groups. The nutrient digestibility was significantly $(p<0.05)$ improved with TRP supplemented diet. The result of the organ weight recorded showed the weight of the visceral organs such as heart, liver, lungs, spleen, pancreas and the gizzard relative to body weight were not significantly $(p>0.05)$ affected by the turmeric supplemented diet compared with the control group, whereas the dressed weight, the size of the kidney, proventriculus and the gall bladder relative to body weight were significantly $(p<0.05)$ increased, although no statistical difference between the $0.25 \%$ and $0.75 \%$ inclusion groups compared with the control group. The significant $(p<0.05)$ increase in the size of proventriculus which is responsible for the mechanical storage of the ingested feed could be attributed to the effect of turmeric supplemented diet compared to control. Also, the gall bladder contained significantly $(p<0.05)$ increased volume of the bile. In conclusion, Turmeric powder supplemented diet at 0.25 and $0.5 \%$ inclusions performed better in improving the growth of Nigerian indigenous cocks, although care should be exercised in prolonged supplementation above $0.5 \%$ inclusion to prevent its deleterious effect on the blood profile. From the findings in this study, to achieve a better growth performance of the Nigerian indigenous cocks with little or no effect on the relative organ weight, $0.5 \%$ inclusion level is highly recommended.

Keywords: Tumeric, Nigerian Indegenous Cock, Body Weight and Organ weight.

\section{Introduction}

Indigenous chicken constitutes $80 \%$ of the 120 million poultry types raised in the rural areas in Nigeria (RIM, 1992). They are selfreliant and hardy birds with the capacity to withstand harsh weather condition and adaptation to adverse environment. They are known to possess qualities such as the ability to hatch their own eggs, brood and scavenge for major parts of their food and possess appreciated immunity from endermic diseases. Their products are preferred by the majority of Nigerians because of the pigmentation, taste, leanness and suitability for special dishes (Horst, 1989). The outputs (egg and meat) are readily available to villagers and people in urban, semi-urban areas thus serve as a good source of protein in their diet, in the same vein, they serve as good source of income (Sonaiya et al.,1999). The local chicken of Nigeria is small in size and grow slowly. There have been reports on the characterization of the local chicken in Nigeria and its potential for egg and meat production (Adebambo, 2005). Even 


\section{Physiological response of Nigerian indigenous cocks}

though the productivity of local chicken is poor, they are very important to withstand certain harsh environmental conditions, can perform better under poor management than cross and exotic breeds, they are also well known to possess desirable characters such as ideal mother, good sister, hatch their eggs, excellent foragers, resistant to common poultry diseases and special meat and egg qualities (flavor), hard egg shells ( Abdelqader et al., 2007). Bioactive plant substance in which have been proved to be very effective in animal nutrition may include the stimulation of appetite and feed intake, improvement of endogenous digestive enzyme secretion, activation of immune response, antibacterial, antiviral and antioxidant actions (Toghyani et al., 2010; 2011). Turmeric (Curcuma longa) is a tropical plant native of Southern and South-eastern tropical Asia. Curcumin is the main important bioactive ingredient responsible for the biological activity of turmeric. Curcumin has been shown to have several biological effects exhibiting antiinflammatory (Holt et al., 2005), antioxidant (Igbal et al., 2003) and hypolipidaemic (Ramiriz-Toritosa et al., 1999). It is used in gastrointestinal and respiratory disorders (Anwarul et al.,2006). The significant biological properties of turmeric powder make it a potential substitute for feed antibiotics in livestock diets. A number of studies have been conducted to evaluate its effects on the performance of broiler chickens (Suriya $e t$ al., 2012; Nayaka et al., 2013; AbouElkhair et al., 2014 and Olukosi and Dono,
2014). However, the results of these studies have been inconsistent keeping in view of the medicinal attributes of Curcuma longa, the purpose of this study therefore was to evaluate the physiological response of the indigenous cocks fed diets Turmeric Rhizome powder.

\section{Materials and methods}

The research was carried out in the Poultry Unit of the University Teaching and Research Farm of Michael Okpara University of Agriculture, Umudike, Abia State in the South Eastern Nigeria. Umudike falls within latitude $5^{\circ} 28^{\prime}$ North and longitude $07^{\circ} 35^{\prime}$ East and lies at an altitude of $112 \mathrm{~m}$ above sea level. The location has an annual precipitation rainfall of 177 $2,000 \mathrm{~cm}$ per annum, (April-October) and a short period of dry season (NovemberMarch) with a relative humidity of about $50-90 \%$ and monthly temperature range of $17^{\circ} \mathrm{C}-36^{\circ} \mathrm{C}$. (Meteorological StationNRCRI, Umudike, 2017).

The harvested rhizomes of turmeric plant that was used for this study was obtained from a reliable source. The rhizomes were carefully washed, peeled and steamed to remove the raw odour. It was dried in the oven at a temperature of $65^{\circ} \mathrm{C}$. The dried rhizomes were polished to remove the rough surface by handpicking and finally milled into turmeric rhizome powder meal using hammer mill. The meal was then used to formulate the bird's experimental diet containing $0.00,0.25,0.50$ and $0.75 \%$ for treatments $\mathrm{T} 1, \mathrm{~T} 2, \mathrm{~T} 3$, and $\mathrm{T} 4$, respectively. The gross composition of the experimental diet with different levels of TRP Powder is shown in Table 1 . 
Table 1: Gross composition of the experimental diet with different level (\%) of turmeric rhizome powder

\begin{tabular}{lcccc}
\hline \multicolumn{1}{c}{ Ingredient } & $\boldsymbol{T}_{\mathbf{1}} \mathbf{0 \%}$ & $\mathbf{T 2} \mathbf{0 . 2 5 \%}$ & $\mathbf{T 3} \mathbf{0 . 5 0 \%}$ & $\mathbf{T 4} \mathbf{0 . 7 5 \%}$ \\
\hline Maize & 47.3 & 47.3 & 47.3 & 47.3 \\
Soya bean meal & 21 & 21 & 21 & 21 \\
Wheat offal & 18 & 18 & 18 & 18 \\
Bone meal & 2 & 2 & 2 & 2 \\
Palm kernel cake & 10 & 10 & 10 & 10 \\
Premix & 0.25 & 0.25 & 0.25 & 0.25 \\
Salt & 0.25 & 0.25 & 0.25 & 0.25 \\
Methionine & 0.1 & 0.1 & 0.1 & 0.1 \\
Lysine & 0.1 & 0.1 & 0.1 & 0.1 \\
Total & $\mathbf{1 0 0}$ & $\mathbf{1 0 0}$ & $\mathbf{1 0 0}$ & $\mathbf{1 0 0}$ \\
Turmeric & 0 & 0.25 & 0.50 & 0.75 \\
Calculated Composition of TRP & & & \\
Crude Protein & 16.02 & 16.02 & 16.02 & 16.02 \\
ME (kcal/kg) & 2,691 & 2,691 & 2,691 & 2,691 \\
\hline
\end{tabular}

\section{Management of experimental animals}

Sixty 8weeks old matured normal feathered local cocks were used for this experiment. The birds were procured from Oriegbe Market in Abakaliki, Ebonyi State. The birds were weighed, and then randomly assigned to four experimental diets of 4 treatment groups of 15 birds per treatment. Each treatment group was further divided into 3 replicates giving 5 birds per replicate per treatment group. The levels of Turmeric Rhizome Powder (TRP) that was included in the diet were $0.0,0.25,0.50$ and $0.75 \%$ represented as $\mathrm{T}_{1}, \mathrm{~T}_{2}, \mathrm{~T}_{3}, \mathrm{~T}_{4}$, respectively (Table 1). Treatment $1\left(\mathrm{~T}_{1}\right)$ which contained no TRP was used as the control. The birds were raised for 6 weeks in deep litter. Feed and water were supplied ad-libitum. The trial lasted 45 days. Four weeks after TRP administration, two cocks from each replicate were selected and the final weigh of the birds were taken.

\section{Statistical analysis}

Data collected in all the parameters measured were subjected to Analysis of Variance (ANOVA) in a Completely Randomized Design (CRD) as outlined by Steel and Torrie (1980). The treatment means were separated using Duncan's New Multiple Range Test at 5\% probability as described by Obi (1990).

\section{Results and discussion Effect of tumeric on growth performance of Nigerian indigenous cocks fed diet with graded levels of tumeric (Cucumma longa)}

The effect of turmeric on the growth performance indices of Nigerian indigenous cocks fed diet with graded levels of tumeric (Cucumma longa) is shown in Table 2. Although, all the groups received same quantity of feed ( $400 \mathrm{~g} / \mathrm{day})$, but the quantity of voluntary feed intake/bird/gram, the amount of leftover (feed refused), the average weight gain/bird/gram, the Feed Conversion Ratio and feed efficiency were significantly $(\mathrm{p}<$ 0.05 ) varied between the tumeric treated groups and control group. The result showed that the birds in the $0.0 \%$ tumeric inclusion level voluntarily consumed significant $(p<0.05)$ greater quantity of the feed compared with the birds placed on turmeric supplement at various inclusion levels. The lower voluntary feed intake recorded in the turmeric groups could be due to depressed appetite as the turmeric concentration was increased as shown by the quantity of left overs, though this 


\section{Physiological response of Nigerian indigenous cocks}

depressed appetite did not significantly ( $\mathrm{p}>$ 0.05 ) differ among the treatment groups. This observation is very similar to the studies of Habeeb et al. (1994); Prasad and Karim (1996) and Marai et al. (2006). The birds in the turmeric groups with higher inclusion levels of 0.5 and $0.75 \%$ significantly $(p<0.05)$ gained more weight compared with the control. The insignificant $(p>0.05)$ difference in the average weight gain in $0.25 \%$ compared with control could be due to lower inclusion level of the turmeric powder. Basavaraji et al., (2010) reported similar finding when the turmeric powder was included at $0.25 \%$ compared with the $0.0 \%$ turmeric group. The relatively lower average weight gain of birds in $0.75 \%$ inclusion group compared to those of birds in $0.5 \%$ inclusion level may be due to increased depression of appetite at higher inclusion of the turmeric. This finding is in agreementwith the observation made by Marai et al. (2006), that $0.5 \%$ inclusion of turmeric powder significantly increase weight gain in chicks, and with Durrani et al. (2006) who reported that at $0.25 \%$ (lowest) and $1.00 \%$ (highest) levels of turmeric had no significant effect on body weight but at $0.5 \%$ level, birds gained significantly higher body weight. In this study the birds at $0.5 \%$ inclusion gained $121.33 \pm 14.70 \mathrm{~g}$ compared with $105.66 \pm$ $25.02 \mathrm{~g}$ at $0.25 \%$ inclusion and $114.00 \pm$ $12.61 \mathrm{~g}$ at $0.75 \%$ inclusion. This significant effect of the turmeric powder on weight gain however disagreed with the study done by Emadi and Kermanshashi (2006) who reported that at $0.25,0.5$ and $0.75 \%$ levels of turmeric, there was no significant effect on the weight gain of chicks fed turmeric supplemented feed compared with chicks fed non-tumeric supplemented feed.

Ramirez-Tortosa et al. (1999) and Marai et al. (2006) reported a direct relationship between FCR and average weight gain of birds and rabbit, respectively fed with turmeric powder. It was observed that birds in the turmeric groups gained an average weight of $1 \mathrm{~g}$ by consuming little quantity range $0.52-0.60 \mathrm{~g}$ of the formulated feed whereas birds in the control group consumed about $2 \mathrm{~g}$ of the $0.0 \%$ turmeric formulated feed to gain an equivalent of $1 \mathrm{~g}$ of body weight. This means that turmeric powder at the various inclusions, elicited significantly $(\mathrm{p}<0.05)$, better FCR compared with the control. The increased percentage feed efficiency observed in the turmeric groups range from $139.31 \pm 23.81$ to $169.11 \pm 17.83 \%$ could be due to increased activity of digestive enzymes such as trypsin, chymotrypsin, and amylase in the turmeric groups compared with the non-turmeric group, which increased the digestibility of the nutrients contained in the formulated feed. Patel and Srinivasan (2000); Salin and Kucuk (2001) and Kiran (2005) reported similar observations.

Table 2: Effect of turmeric powder on growth performance of Nigerian indigenous cocks fed diet with graded levels of tumeric (Cucumma longa)

\begin{tabular}{lllll}
\hline & \multicolumn{3}{c}{ Treatment (Turmeric) } \\
\cline { 2 - 5 } & \multicolumn{1}{c}{$\mathrm{T}_{\mathbf{1}}$} & $\mathbf{T}_{\mathbf{2}}$ & $\mathbf{T}_{\mathbf{3}}$ & $\mathbf{T}_{\mathbf{4}}$ \\
& $\mathbf{0 . 0 \%}$ & $\mathbf{0 . 2 5 \%}$ & $\mathbf{0 . 5 \%}$ & $\mathbf{0 . 7 5 \%}$ \\
Parameters & & & & \\
\hline Average quantity of feed given $(\mathrm{g})$ & $400.00 \pm 0.00$ & $400.00 \pm 0.00$ & $400.00 \pm 0.00$ & $400.00 \pm 0.00$ \\
Voluntary Feed intake/bird/g & $85.76 \pm 2.57^{\mathrm{a}}$ & $67.75 \pm 1.45^{\mathrm{b}}$ & $67.64 \pm 1.41^{\mathrm{b}}$ & $67.38 \pm 1.07^{\mathrm{b}}$ \\
Feed refusal/bird/g & $39.33 \pm 1.76^{\mathrm{c}}$ & $53.42 \pm 2.71^{\mathrm{b}}$ & $64.16 \pm 2.41^{\mathrm{a}}$ & $67.13 \pm 2.21^{\mathrm{a}}$ \\
Average Weight gain/bird (g) & $51.03 \pm 19.25^{\mathrm{b}}$ & $105.66 \pm 25.20^{\mathrm{ab}}$ & $121.33 \pm 14.70^{\mathrm{a}}$ & $114.00 \pm 12.16^{\mathrm{a}}$ \\
Feed Conversion Ratio (FCR) & $2.04 \pm 0.65^{\mathrm{a}}$ & $0.52 \pm 0.25^{\mathrm{b}}$ & $0.57 \pm 0.08^{\mathrm{b}}$ & $0.60 \pm 0.06^{\mathrm{b}}$ \\
Feed Efficiency (\%) & $63.14 \pm 22.59^{\mathrm{b}}$ & $139.31 \pm 23.81^{\mathrm{a}}$ & $179.69 \pm 22.88^{\mathrm{a}}$ & $169.11 \pm 17.83^{\mathrm{c}}$ \\
\hline
\end{tabular}

Note: Values are presented as means \pm S.E.M, where $\mathrm{a}, \mathrm{b} \& \mathrm{c}$ represents significant differences. Values of $\mathrm{p}<0.05$ is consider ed significant. 


\section{Urom, Inyang, Onunkwo and Ewa}

Relative organ weight of Nigerian indigenous cocks fed diet with graded levels of tumeric (Cucumma longa)

The relative organ weight of Nigerian indigenous cocks fed diet with graded levels of tumeric (Cucumma longa) is presented in Table 3. The result shows the weight of the visceral organs such as heart, liver, lungs, spleen, pancreas and the gizzard relative to body weight were not significantly $(p>0.05)$ affected by the turmeric supplemented diet compared with the control group, whereas the dressed weight, the size of the kidney, proventriculus and the gall bladder relative to body weight were significantly $(\mathrm{p}<0.05)$ increased, although no statistical difference was observed between the $0.25 \%$ and $0.75 \%$ inclusion groups compared with the control group. The significant $(p<0.05)$ increase in the size of proventriculus which is responsible for the mechanical storage of the ingested feed could be attributed to the effect of turmeric supplemented diet compared to control. Also, the gall bladder contained significantly $(p<0.05)$, increased volume of the bile and this increase in the bile volume could be as a result of increased activity on the digestible nutrient by the pancreatic organ of birds at $0.75 \%$ inclusion. It is very important to note that all the birds in the turmeric supplemented diet groups, weighed heavier $(p<0.05)$ than the birds in the control group which implies that feeding birds with turmeric supplemented diet at the various inclusions used in this study could improve the market size or growth performance of the birds. This study showed great similarities to the works reported by Patel and Srinivasan (2000); Kazim et al. (2001); Ishita et al. (2004) and Marai et al. (2006).

Table 3: Effect of turmeric on the relative Organ Weight / Viscerosomatic Index of Nigerian indigenous cocks fed diet with graded levels of tumeric (Cucumma longa)

\begin{tabular}{lcccl}
\hline & \multicolumn{4}{c}{ Treatment (Turmeric) } \\
\cline { 2 - 5 } & $\mathbf{T}_{\mathbf{1}}$ & $\mathbf{T}_{\mathbf{2}}$ & $\mathbf{\mathbf { T } _ { 3 }}$ & $\mathbf{T}_{\mathbf{4}}$ \\
& $\mathbf{0 . 0 \%}$ & $\mathbf{0 . 2 5 \%}$ & $\mathbf{0 . 5 \%}$ & $\mathbf{0 . 7 5 \%}$ \\
\hline Parameters & & & & \\
\hline Dressed Weight (kg) & $1.08 \pm 0.03^{\mathrm{b}}$ & $1.25 \pm 0.06^{\mathrm{ab}}$ & $1.33 \pm 0.08^{\mathrm{a}}$ & $1.33 \pm 0.02^{\mathrm{a}}$ \\
Heart (\%) & $0.59 \pm 0.09$ & $0.57 \pm 0.00$ & $0.57 \pm 0.02$ & $0.60 \pm 0.49$ \\
Liver (\%) & $1.81 \pm 0.31$ & $1.77 \pm 0.13$ & $1.75 \pm 0.12$ & $1.77 \pm 0.19$ \\
Lungs (\%) & $0.64 \pm 0.31$ & $0.62 \pm 0.09$ & $0.76 \pm 0.06$ & $0.71 \pm 0.08$ \\
Kidney (\%) & $0.49 \pm 0.04^{\mathrm{a}}$ & $0.33 \pm 0.01^{\mathrm{b}}$ & $0.41 \pm 0.03^{\mathrm{ab}}$ & $0.38 \pm 0.03^{\mathrm{ab}}$ \\
Proventiculus (\%) & $0.34 \pm 0.03^{\mathrm{b}}$ & $0.39 \pm 0.01^{\mathrm{ab}}$ & $0.49 \pm 0.04^{\mathrm{a}}$ & $0.43 \pm 0.02^{\mathrm{ab}}$ \\
Spleen (\%) & $0.14 \pm 0.01$ & $0.13 \pm 0.01$ & $0.13 \pm 0.05$ & $0.08 \pm 0.00$ \\
Gall Bladder (\%) & $0.06 \pm 0.01^{\mathrm{b}}$ & $0.07 \pm 0.00^{\mathrm{ab}}$ & $0.07 \pm 0.00^{\mathrm{ab}}$ & $0.11 \pm 0.02^{\mathrm{a}}$ \\
Pancrease (\%) & $0.18 \pm 0.03$ & $0.17 \pm 0.00$ & $0.19 \pm 0.01$ & $0.15 \pm 0.01$ \\
Gizzard (\%) & $3.33 \pm 0.48$ & $3.20 \pm 0.33$ & $4.03 \pm 0.12$ & $3.16 \pm 0.59$ \\
\hline
\end{tabular}

Note: Values are presented as means \pm S.E.M, where a and $\mathrm{b}$ represent significant differences. Values of $\mathrm{p}<0.05$ is considered significant.

\section{Conclusion and recommendations}

The type of food supplement or diet formulations and feeding regimen have a great impact on the growth performance of the Nigerian indigenous chickens which has a direct influence on their reproductive performance. The result of the growth performance showed that supplementing the diet of our local cocks with Turmeric powder especially, at $0.5 \%$ inclusion level will enhance the weight gain and the average market size of about $1.33 \mathrm{~kg}$ which will make it comparable to other hybrid chickens used as meat. Although, the 


\section{Physiological response of Nigerian indigenous cocks}

Turmeric powder has no significant deleterious effect on the major organs which make it very safe for inclusion in the diet of our local indigenous cocks, but prolonged usage could result in mild effects on the birds.

\section{References}

Abdelqader, A., Wollny, C. B. A. and Gauly, M. 2007. Characterization of local chicken production systems and their potential under different levels of management practice in Jordan Tropical Animal Health and Production, 39 (3): 155- 64.

Abou-Elkhair, R., Ahmed, H. A. and Selim, S. 2014, ffects of black pepper (Piper nigrum), turmeric powder (Curcuma longa) and coriander seeds (Coriandrum sativum) and their combinations as feed additives on growth performance, carcass traits, some blood parameters and humoral immune response of broiler chickens. Asian-Australas. Journal of Animal Science, 27: 847-854.

Adebambo, O.A. 2005. Indigenous poultry breeds genetic improvement for meat and eggs. Proceedings of the 1st International Poultry Summit, Feb. 20-25, Ota, Ogun State, pp:18.

Anwarul, H. G., Abdul, J., Muhammad, N. and Kashif, M. 2006. Pharmacological basis for the use of turmeric in gastrointestinal and respiratory disorders. Life Science, 76: 3089-3105.

Basavaraj, M., Nagabhushana, V., Prakash, N., Mallikarjunappa, S., Appannavar, M. M. and Prashanth, W. 2010. Effect of dietary supplementation of Pulvis
Curcuma Longa on the voluntary feed intake, nutrient digestibility and Growth performance of Broiler rabbits under summer stress. Veterinary World, 3(8): 369-372.

Durrani, F. R., Mohammed, I., Asal, S., Shhail, S. M., Naila, C. and Durrani, Z. 2006. Effect of different levels of feed added turmeric (Curcuma longa) on the performance of broiler chicks. Journal of Agricultural Biological Science, 1, 9-11.

Emadi M and Kermanshahi, H. 2006. Effect of turmeric rhizome powder on performance and carcass characteristics of broiler chickens. International Journal of Poultry Science, 5: 1069-1072.

Habeeb, A., Marai, F., El-Sayaid, G. H. and Nessem, Z. 1994. Effects of internal and external cooling techniques on growth and physical functions of New Zealand White and Californian rabbits maintained under hot summer conditions of Egypt. Proc. Ist Int. conf. on Rabbit Prod. In hot climates, Cairo, Egypt 6-8 September 626-633.

Holt, P. S., Geden, C. J., Moore, R. W. and Gast, R. K. 2007. Isolation of Salmonella enterica serovar Enteritidis from houseflies (Musca domestica) found in rooms containing Salmonella serovar Enteritidis-challenged hens. Applied Environmental Microbiology, 73:6030-6035.

Horst, P. 1989. Native fowls as reservoir for genomes and major genes with direct and indirect effects on adaptability and their potential for tropical oriented breeding plans. Animal Breeding Abstract, 53: 93- 
101

Igbal, M., Cawthon, D., Wideman Jr, R. F. and Bottje, W. G. 2003. Lung mitochondria dysfunction in pulmonary hypertension syndrome II. Oxidative stress and inability to improve function with repeated additions of adenosine diphosphate. Poultry Science, 80:656-665.

Ishita, C., Kaushik, B., Uday, B. and Ranajit, K. B. 2004. Turmeric and curcumin biological actions and medicinal applications. Current science, 87(1): 44 -53.

Kazim, S., Nurhan, S. and Sema, Y. 2001. Effects of Vitamic C and Vitamin E on lipid peroxidation, blood serum metabolites and mineral concentration of laying hens reared at high ambient temperature. Biological Trace Element Research, 85(1): 35-45.

Kiran, L. 2005. Effect of Jojoba (Simmondsia chinensis) meal on the performance of the broiler rabbits. M.V.Sc thesis, KVAFSU Bidar.

Marai, I. F. M., Ayyat, M. and AbdelMonem, U. M. 2006. Growth performance, blood components and slaughter traits of New Zealand white male rabbits as affected by dietary supplementation with calcium, sodium or potassium in subtropical Egypt. Tropical and Subtropical Agro ecosystems, 6: $149-156$.

Nayaka, H. B. S., Umakantha, B., Ruban, S. W., Murthy, H. N. N. and Narayanaswamy, H. D. 2013. Performance and hematological parameters of broilers fed neem, turmeric, vitamin e and their combinations. Emirate Journal of Food Agriculture, 25: 483-488.
Nwosu, C. C. 1979. Characterization of the local chicken in Nigeria and its potential for egg and meat production. Proceedings of the 1st National Seminar on Poultry Production, Dec. 11-13, Ahmadu Bello University, Zaria, pp: 187-21

Obi I. U 1990. Statistical Methods of Detecting differences between treatment means $2^{\text {nd }}$ edition Snaap,Press, Enugu,Nigeria.

Olukosi, O. A. and Dono, N. D. 2014. Modification of digesta $\mathrm{pH}$ and intestinal morphology with the use of benzoic acid or phytobiotics and the effects on broiler growth performance and nutrient utilization. Journal of Animal Science, 92: 3945-3953.

Patel, K. and Srinivasan, K. 2000. Influence of dietary spices and their active principles on pancreatic digestive enzymes in albino rats. Nahrung, 44:42-46.

Prasad, Rajendra and Karim, S. A. 1996. Nutrient intake and utilization by rabbits in different seasons. Indian Journal of Animal Science, 66(1): 74-77.

Ramirez-Tortosa, M. C., Mesa, M. D., Aguilera, M. C., Quiles, J. L. and Baro, L. 1999. Oral administration of a turmeric extract inhibits LDL o x i d a t i o $\mathrm{n} \mathrm{a} \mathrm{d} h$ a $\mathrm{s}$ hypocholesterolemic effects in rabbits with experimental atherosclerosis. Atherosclerosis 147, 371-378.

RIM (Resources Inventory and Management Limited), 1992. Nigerian National Livestock Survey, federal Department of Livestock and Pest Control Services, Abuja, Nigeria. Pp 287.

Sahin, K. and Kucuk, O. 2001. Effects of Vitamin C and carcass characteristics of Japanese quails 


\section{Physiological response of Nigerian indigenous cocks}

reared under chronic heat stress $\left(34^{\circ} \mathrm{C}\right)$. Journal of Animal Physiology and Animal Nutrition, 85:335-342.

Sonaiya, E. B., Branckaert, R. D. S. and Gueye, E. F. 1999. Research and development options for family poultry. First INFPD/FAO Electronic Conference on Family Poultry

Steel, R. G. D and Torrie J. H 1980. Principles of Procedures of Statistics and biometric.

Suriya, R., Zulkifli, I. and Alimon, A. R. 2012. The Effect of Dietary Inclusion of Herbs as growth Promoter in Broiler Chickens. Journal of Animal and Veterinary Advances, 11: 346-350.
Toghyani, M., Toghyani, M., Gheisari, A., Ghalamkari, G. and Eghbalsaied, A. 2011. Evaluation of cinnamon and garlic as antibiotic growth promoter substitutions on performance, immune responses, serum biochemical and haematological parameters in broiler chicks. Livestock Science, 138: 167-173.

Received: $30^{\text {th }}$ August, 2019 Accepted: $19^{\text {th }}$ December, 2019 